OPEN ACCESS

Edited by:

Julio Lumbreras,

Polytechnic University of

Madrid, Spain

Reviewed by:

Jose Guillermo Cedeno Laurent,

Harvard University, United States

Anzhelika Antipova,

University of Memphis, United States

${ }^{*}$ Correspondence:

Maria D. Castillo

mdcastillo@gwu.edu

Specialty section:

This article was submitted to

Health and Cities,

a section of the journal

Frontiers in Sustainable Cities

Received: 31 August 2021

Accepted: 20 October 2021

Published: 15 November 2021

Citation:

Castillo MD, Anenberg SC, Chafe ZA,

Huxley R, Johnson LS, Kheirbek I,

Malik M, Marshall JD, Naidoo $S$, Nelson ML, Pendleton NV, Sun Y, van

den Broek d'Obrenan $\mathrm{H}$ and Kinney PL (2021) Quantifying the Health Benefits of Urban Climate

Mitigation Actions: Current State of the Epidemiological Evidence and

Application in Health Impact Assessments.

Front. Sustain. Cities 3:768227. doi: 10.3389/frsc.2021.768227

\section{Quantifying the Health Benefits of Urban Climate Mitigation Actions: Current State of the Epidemiological Evidence and Application in Health Impact Assessments}

\author{
Maria D. Castillo ${ }^{1 *}$, Susan C. Anenberg ${ }^{1}$, Zoe A. Chafe ${ }^{2}$, Rachel Huxley ${ }^{2}$, \\ Lauren S. Johnson ${ }^{1}$, Iyad Kheirbek ${ }^{2}$, Maha Malik' ${ }^{1}$, Julian D. Marshall ${ }^{3}$, Seneca Naidoo' \\ Margaret L. Nelson ${ }^{1}$, Nicholas V. Pendleton ${ }^{1}$, Yuantong Sun ${ }^{4}$, \\ Honorine van den Broek d'Obrenan ${ }^{2}$ and Patrick L. Kinney ${ }^{4}$
}

\footnotetext{
'Department of Environmental and Occupational Health, George Washington University Milken Institute School of Public Health, Washington, DC, United States, ${ }^{2}$ C40 Cities Climate Leadership Group Inc., New York, NY, United States,

${ }^{3}$ Department of Civil and Environmental Engineering, University of Washington, Seattle, WA, United States, ${ }^{4}$ Department of Environmental Health, Boston University School of Public Health, Boston, MA, United States
}

While ambitious carbon reduction policies are needed to avoid dangerous levels of climate change, the costs of these policies can be balanced by wide ranging health benefits for local communities. Cities, responsible for $\sim 70 \%$ of the world's greenhouse gas (GHG) emissions and home to a growing majority of the world's population, offer enormous opportunities for both climate action and health improvement. We aim to review the current state of knowledge on key pathways leading from carbon mitigation to human health benefits, and to evaluate our current ability to quantify health benefits for cities around the world. For example, because GHGs and air pollutants are both released during fuel combustion, reducing fuel burning can reduce both GHGs and air pollutants, leading to direct health benefits. Air quality improvements may be particularly important for city-scale climate action planning because the benefits occur locally and relatively immediately, compared with the global and long-term (typically, decades to centuries) benefits for the climate system. In addition to improved air quality, actions that promote active transport in cities via improved cycling and pedestrian infrastructure can reap large cardiovascular health benefits via increased physical activity. Exposure to green space has been associated with beneficial health outcomes in a growing number of epidemiological studies and meta-analyses conducted around the world. Finally, noise is an underappreciated environmental risk factor in cities which can be addressed through actions to reduce motor vehicle traffic and other noise sources. All of these environmental health pathways are supported by well-conducted epidemiological studies in multiple locales, providing quantitative exposure-response data that can be used as inputs to health impact assessments (HIAs). However, most epidemiologic evidence derives from studies in high-income countries. It is unclear to what extent such evidence is directly transferable for policies in low- and middle-income countries (LMICs). This gap calls 
for a future focus on building the evidence based in LMIC cities. Finally, the literature suggests that policies are likely to be most effective when they are developed by multidisciplinary teams that include policy makers, researchers, and representatives from affected communities.

Keywords: climate action plans, urban health, green space, air quality, physical activity, noise exposure, health equity

\section{INTRODUCTION}

There is growing awareness that urgent global action is needed to avoid dangerous levels of climate change this century. To keep global mean temperature change from exceeding the $1.5^{\circ} \mathrm{C}$ threshold established by the 2015 Paris Agreement will require major transformations across a range of sectors including energy, industry, transportation, buildings, agriculture, waste, and land use (IPCC, 2018; International Energy Agency, 2021). While challenging to achieve, the transformative changes that are needed represent an insurance policy against future catastrophic levels of climate change and extreme events. Importantly, many of the actions needed to achieve a net zero carbon world economy by 2050 will bring immediate and local benefits to society in terms of health, jobs, energy security, and quality of life (ClimateWorks Foundation World Bank Group, 2014). As noted in Figure 1, climate mitigation can lead to improved health outcomes while also achieving greenhouse gas (GHG)/carbon emission goals (Jack and Kinney, 2010; Hess et al., 2020; C40 Cities, 2021a; Watts et al., 2021). These health benefits, often referred to as "co-benefits" in the literature, tend to accrue quickly, and in close proximity to where the carbon reduction actions are implemented, thereby benefiting local communities.

Sectors targeted for carbon mitigation may be linked to adverse health outcomes through a variety of pathways, including clean air and water, opportunities for physical activity and exposure to green space, reduced noise, and others. Cities, which are responsible for $\sim 70 \%$ of the world's GHG emissions (Moran et al., 2018) and are home to about half of the world's population, offer enormous opportunities for both climate action and health improvement. Cities are thus seen as vital to climate mitigation efforts and environmental health strategies (Rosenzweig et al., 2010). A fuller understanding of, and accounting for, the health benefit pathways that flow from carbon action can help build stronger political will to tackle climate change mitigation at the local level. At the 2015 United Nations Climate Change Conference, COP21, in Paris, UN-Habitat launched the "Guiding Principles for City Climate Action Planning" which notes that climate mitigation is not mutually exclusive with development (UN-Habitat., 2015). The human health argument for action however was not well-articulated, due in part to the fragmentary nature of the recent literature on health benefits, and the range of inputs and analytical methods represented across studies (Hess et al., 2020).

The goal of this paper is to summarize health evidence on four key exposure-response pathways that can be modified in health-beneficial ways via climate action: reduced air pollution, reduced noise, increased green space, and increased physical activity. While the focus is on mitigation, some mitigation actions also can be viewed as building adaptive capacity or resilience to ongoing or worsening climate extremes. We review each pathway, summarize the underlying environmental health literature, and reach conclusions regarding which health outcomes have sufficiently robust support in the epidemiological literature to justify their application in health impact assessments (HIAs) of carbon mitigation strategies. Using the C40 Cities Climate Leadership Group (also referred to as C40 Cities) as an example, we conclude with an illustration of how analyses of health benefits of climate mitigation actions can be used as inputs to policy decisions in cities.

\section{FRAMEWORK FOR ASSESSING HEALTH BENEFITS OF URBAN CLIMATE MITIGATION ACTIONS}

Urban actors engaged in developing climate mitigation actions usually begin with a quantitative assessment of current carbon emission sources within their city (C40 Cities, 2021a). Source categories can then be prioritized for action based on a range of factors, including their emission magnitudes, economic importance, availability of substitutes, and health and equity considerations. As suggested in Figure 1, once taken, a control action (e.g., conversion to a low carbon energy source for power generation) can lead to "outputs" consisting of changes in the system (e.g., fuel conversion or technology incentives), and one or more "outcomes" that are necessary for the impact to occur (e.g., a reduction in $\mathrm{CO}_{2}$ emissions and reductions in air pollution emissions and exposure), and finally to "impacts" related to both emissions and health (e.g., achieving near-term carbon emission goals, and reducing healthdamaging air pollution). For this review, we focus on four pathways for which the health literature is currently most robust: air quality, green space, noise, and physical activity (Figure 2).

Changes in exposure may lead directly to health benefits, as is the case for clean air or noise reduction, indirectly through reducing other environmental risks such as decreased heat exposure with increased access to green spaces, or may operate through downstream behavioral changes that are made possible by the change in exposure, such as an increase in physical activity in response to building bike lanes. While other studies have conducted systematic reviews of the evidence for individual environmental health exposure-response pathways (most often with a focus on air quality), our goal is to explore the applicability of the epidemiological evidence for 

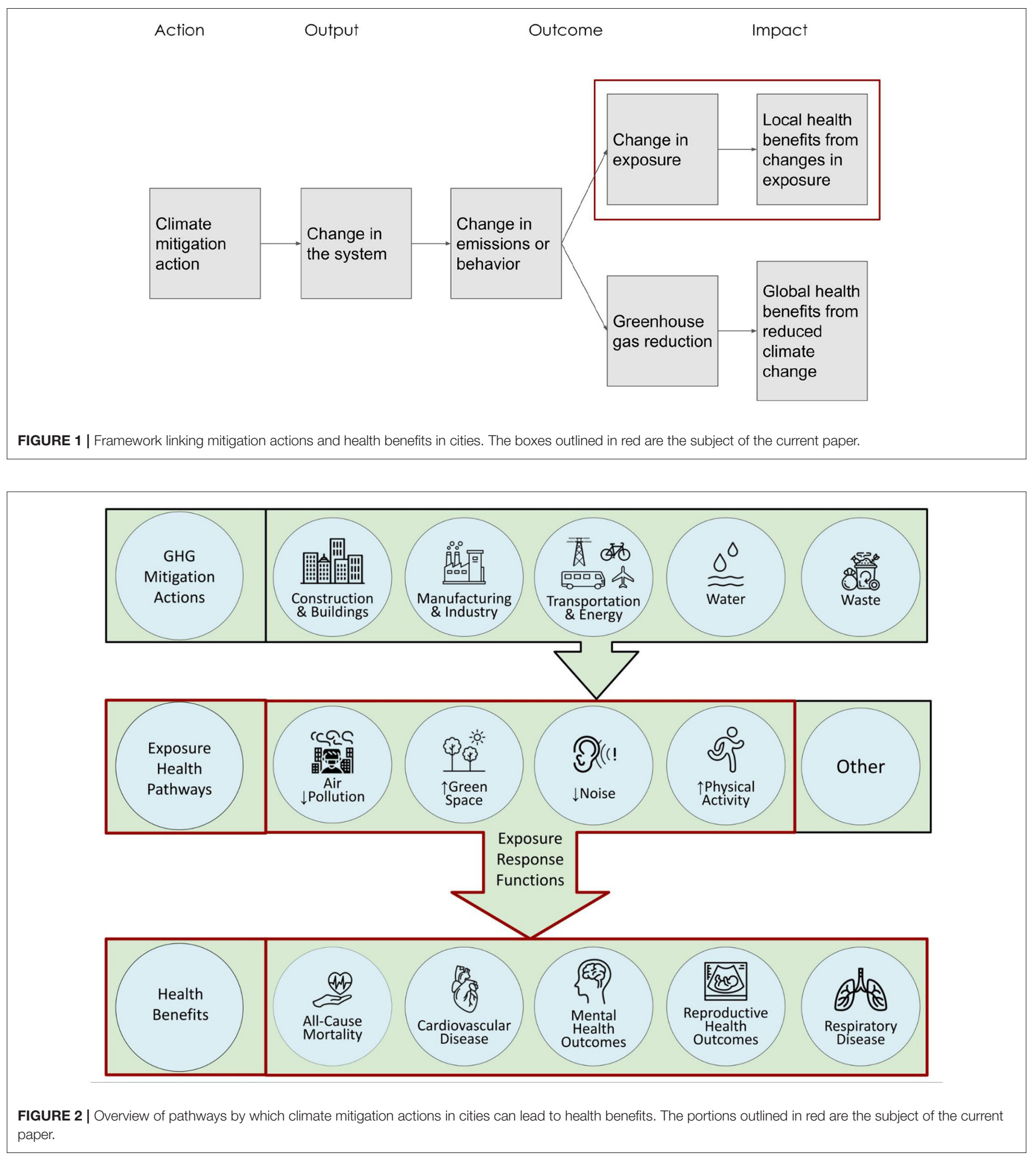

quantifying health benefits of urban climate actions across a range of relevant exposure-response pathways available to cities. We do not address the challenging, upstream task of modeling the impacts of mitigation actions on changes in exposures.
The method of HIA is used to estimate potential changes in health outcomes associated with carbon mitigation actions. Health impact assessment is an increasingly common tool in the analysis of current health burdens, as well as health implications of proposed environmental policies (Mindell and Joffe, 2003). 
The widely cited global burden of disease (GBD) study is one prominent example (GBD 2019 Risk Factors Collaborators, 2020). In the case of estimating the health benefits of GHG mitigation, HIAs quantify changes in health outcomes (e.g., all-cause mortality; disease-specific morbidity) associated with changes in exposure to risk factors (e.g., air pollution; lack of physical activity) that could result from actions taken to reduce carbon emissions (e.g., shifting from coal-fired to renewable energy generation).

Essential inputs include data on current rates of the health outcome of interest in the population being analyzed, the change in exposure that would occur following the mitigation action, and the exposure-response function (ERF) linking changes in exposure to changes in the health outcome. The ERF is derived from robust epidemiologic studies that report quantitative summaries of the association between exposure and outcome. Preferably, ERFs are derived from multiple epidemiology studies or related "meta-analysis" studies, ideally including studies from regions relevant to the population being analyzed.

\section{HEALTH BENEFITS PATHWAYS}

\section{Air Quality}

Many GHGs and air pollutants share common sources, as products of fossil fuel combustion. Fuel consumption for power generation, industrial processes, transportation (including airplanes, shipping, and heavy-, medium-, and light-duty vehicles), agriculture, and residential energy use (e.g., heating, cooking, and lighting), releases $\mathrm{CO}_{2}$ and a mixture of air pollutants (e.g., black carbon, organic carbon), and air pollution precursor emissions (e.g., nitrogen oxides, volatile organic compounds, sulfur dioxide) that form secondary pollutants like fine particulate matter $\left(\mathrm{PM}_{2.5}\right)$ and ozone. Globally, over half of the $\mathrm{PM}_{2.5}$ mortality burden is attributable to coal combustion (McDuffie et al., 2021). Emissions from residential, industrial, and energy sectors contribute an estimated 19, 12, and $10 \%$ of global $\mathrm{PM}_{2.5}$ mortality. However, these fractions differ dramatically around the world, depending on nearby emissions of dust and wildfire smoke, level of development and associated use of solid fuels for residential energy use, and degree of emissions regulation in energy, industry, and transportation sectors.

Many national governments have set health-based standards for ambient levels of these pollutants, such as the National Ambient Air Quality Standards (NAAQS) in the U.S. The World Health Organization (WHO) has also set guidelines for individual ambient (outdoor) and indoor air pollutants. These guidelines state that pollutant concentrations (1-h, 24-h, and/or annual mean concentrations) should not exceed certain levels. For example, the WHO's 2021 guideline for annual average $\mathrm{PM}_{2.5}$ concentrations is $5 \mu \mathrm{g} / \mathrm{m}^{3}$ (World Health Organization, 2021). Because GHGs and air pollutants are both released during fuel combustion, reducing fuel burning would reduce both GHGs and air pollutants. Air quality improvements may be particularly important for city-scale climate action planning, because the benefits occur locally and relatively immediately, compared with the global and long-term (typically, centuries) benefits for the climate system.

Thousands of studies have explored relationships between short- and long-term exposure to $\mathrm{PM}_{2.5}$, ozone, and other air pollutants and a range of health outcomes. Most have been carried out in North America and Europe, though studies are increasingly focusing on other parts of the world where pollution levels remain high. The most recent systematic reviews by the USEPA found that long-term $\mathrm{PM}_{2.5}$ exposure is causally associated with mortality and cardiovascular effects, and is likely to be causally associated with respiratory effects (US EPA, 2019). For ozone, the USEPA found that long-term exposure is likely to be causally associated with respiratory effects, and short-term exposure is causally associated with respiratory effects and likely to be causally associated with metabolic effects (US EPA, 2020). The Institute for Health Metrics and Evaluation, which leads the prominent GBD Study, has determined that long-term $\mathrm{PM}_{2.5}$ exposure is also associated with diabetes, short gestational age, and low birth weight (GBD 2019 Risk Factors Collaborators, 2020). Other systematic reviews and meta-analysis have been performed. Associations have been quantified for traffic-related air pollution and asthma (Khreis et al., 2017). Heterogeneity among studies, and publication bias, have limited quantifiable associations between air pollution and depression (Fan et al., 2020). Evidence is still emerging that air pollution is associated with higher risk of cognitive decline (Zhang et al., 2018) and dementia (Peters et al., 2019).

Results of these systematic reviews and meta-analyses provide concentration-response factors for individual air pollutants that can be used to assess health impacts of air pollution for countries (e.g., Cohen et al., 2017) and cities worldwide (e.g., Anenberg et al., 2019). One of the most high-profile studies assessing the health burden from air pollution is the GBD Study, which has found that air pollution is the fourth leading risk factor contributing to global mortality (GBD 2019 Risk Factors Collaborators, 2020). Other studies using more linear risk estimates across the $\mathrm{PM}_{2.5}$ concentration range indicate that the GBD $\mathrm{PM}_{2.5}$ mortality burden could be an underestimate (Burnett et al., 2018; Lelieveld et al., 2020). Where available, country-specific epidemiological studies are also used in air pollution HIAs (e.g., Fann et al., 2012, 2017; Lehtomäki et al., 2018). A number of quantitative tools have been developed to systematize air pollution HIAs, including the Environmental Benefits Mapping and Analysis Program (BenMAP) developed by the USEPA (Sacks et al., 2018), AirQ+ (Sacks et al., 2020) developed by the WHO, and the Air Quality Benefits Toolkit (Sacks et al., 2020; C40 Cities et al., n.d) developed by C40 Cities and used by over 30 cities worldwide. These tools range in methods, data inputs, and appropriateness for different applications (Anenberg et al., 2016).

A growing body of literature uses these risk estimates to assess the health benefits of improved air quality associated with GHG mitigation. For example, previous studies have assessed the health benefits of global GHG and short-lived climate pollutant reductions through idealized scenarios (Anenberg et al., 2012; Shindell et al., 2012; West et al., 2013; Harmsen et al., 2020; Vandyck et al., 2020) and via nationally determined contributions 
to the Paris Agreement (Markandya et al., 2018; Sampedro, 2020). Recent studies have also assessed air quality and health benefits of GHG mitigation at national (Xie et al., 2020; Yang et al., 2021), state (Wang et al., 2020), and city scales (Johnson et al., 2020). These studies often find that the global health benefits exceed mitigation costs, though results are more nuanced at national or regional scales (Markandya and Sampedro, 2020).

With the strong relationship between air pollution and mortality, and the high value society places on human health, improvements to air quality and health from GHG mitigation carry high economic value and can be impactful on decisionmaking, including providing motivation for the implementation of more ambitious climate mitigation actions. In a sign that integrated assessments of GHG, air quality, and health are moving beyond the academic literature, air quality, and health improvements have recently been considered in regulations targeting GHG, such as the Clean Power Plan in the U.S. (US EPA, 2015). At the city scale, some urban climate action plans have begun incorporating assessments of air quality and health improvements from local GHG mitigation, either quantitatively or qualitatively (Johnson et al., 2020). However, full quantitative assessments of air quality and health benefits are still limited. This outcome is in part due to the challenge of linking activity changes to emissions, emissions to ambient concentrations, and ambient concentrations to health impacts, which are complex processes. It is also difficult to isolate the proportion of air pollution originating inside vs. outside of the city, which can complicate the use of some analysis methods that depend on source apportionment. Aligning separate GHG and air quality inventories for a city can also be challenging since the processes in developing these inventories are time-consuming and may differ from each other. Several tools are now being developed to make it easier to quantify GHG, air quality, and health changes from changes in activity levels or emissions, including LEAP-IBC (Kuylenstierna et al., 2020) and Pathways-AQ (under development by C40). These tools still need to be scaled up for use in multiple geographical settings and policy contexts.

Globally, many cities with high air pollution levels lack monitoring stations and the necessary data to manage air quality, making it challenging to identify the city with the highest $\mathrm{PM}_{2.5}$ concentration in the world (Martin et al., 2019). However, it is estimated that air pollution-related health risks at the city level vary drastically across the globe (Apte et al., 2015; Achakulwisut et al., 2019; Anenberg et al., 2019). Research on socioeconomic disparities and air pollution exposure has found that people in areas of low socioeconomic status are exposed to higher concentrations of air pollutants in North America as well as in Asia and Africa, though research is more limited outside of North America, while in Europe the findings have been mixed (Hajat et al., 2015). Evidence in the U.S. has shown that people of color are disproportionately exposed to higher levels of $\mathrm{PM}_{2.5}$ pollution (Liu et al., 2021; Tessum et al., 2021), and that lowincome and/or minority populations within cities continue to be inequitably impacted by the air pollution-associated health burden (e.g., Tessum et al., 2019; Colmer et al., 2020; Castillo et al., 2021).

\section{Green Space}

Urban green space can include a broad range of features such as parks, gardens, street trees, trails, and green walls and roofs. In the context of carbon mitigation, green space offers the advantage of sequestering and storing carbon out of the atmosphere. Green space can deliver a number of additional benefits that include localized cooling (Wong and Yu, 2005; Rizwan et al., 2008; Önder and Akay, 2014), reduction of runoff and flooding, improved air quality (Nowak et al., 2014; Rojas-Rueda et al., 2019), reduced noise (Dzhambov et al., 2018), expanded places that promote social interactions (Maas et al., 2009), increased physical activity (Gascon et al., 2016; Twohig-Bennett and Jones, 2018; Kruize et al., 2019), and a range of related health benefits (Frumkin et al., 2017).

Exposure to green space has been associated with beneficial health outcomes in a large and growing number of epidemiological studies and meta-analyses conducted around the world. Some of the research in this field focuses on the effect of green space exposure on specific health outcomes, such as mortality and obesity (Twohig-Bennett and Jones, 2018). Three major meta-analyses (Gascon et al., 2016; Twohig-Bennett and Jones, 2018; Rojas-Rueda et al., 2019) use a variety of methods to measure exposure to green space including normalized difference vegetation index (NDVI), tree canopy, and street tree data, as well as subjective measures of greenness such as self-reported quality of neighborhood green space (Twohig-Bennett and Jones, 2018). Normalized difference vegetation index is a widely used metric of outdoor green space and captures chlorophyll content in the vegetation canopy on a scale from -1 to 1 with values closer to 0 meaning no vegetation, values closer to 1 being very dense vegetation, and values closer to -1 indicating water (Helbich, 2019; Georgiou et al., 2021). Normalized difference vegetation index is now freely available with global coverage at a $30 \mathrm{~m}$ resolution, and has recently been incorporated as a new indicator for over 1,000 global cities as part of the Lancet Countdown on Climate Change and Human Health (Watts et al., 2021). To quantify the impacts of urban green space on health, the WHO European Centre for Environment and Health $(\mathrm{ECEH})$ developed GreenUr, an open-source plug-in for QGIS that helps measure availability and accessibility of green space in cities (GreenUr, 2021).

Research suggests that the relationship between urban vegetation and air pollution is not straightforward. Urban trees play a role in both removing (Hardin and Jensen, 2007) and also contributing to Jenkin et al. (2015) tropospheric ozone $\left(\mathrm{O}_{3}\right)$ concentrations. However, this relationship is complex, depends on environmental variables such as tree type, and only affects some air pollutants. In the systematic review by Gascon et al. (2016), a subset of six studies considered air pollution as a potential confounding factor for the effects of green space and cardiovascular disease or all-cause mortality. Controlling for air pollution, those studies still found health benefits from green space exposure (Gascon et al., 2016).

The lack of green space and the presence of non-reflective, impervious surfaces cause an absence of evapotranspiration to cool the surrounding environment, and instead absorb heat and 
retain it for longer periods of time. These characteristics have amplified changes in heat within urban landscapes (Basara et al., 2010; Chen et al., 2014; Ziter et al., 2019). The combination of these changes to the natural environment produces the Urban Heat Island (UHI), which has been observed in countries worldwide. Patterns of vegetation in cities influence the energy balance of incoming and outgoing radiation, contributing to localized cooling via shading and evapotranspiration. Thus, green spaces and green roofs can be effective tools to counteract the UHI (Solecki et al., 2005; Norton et al., 2015; Shafique et al., 2016; Moss et al., 2019). Tools like the Heat Resilient Cities Benefits Tool, developed by C40 Cities, can help urban planners and policy makers quantify health, economic, and environmental benefits of potential adaptation initiatives (Heat Resilient Cities Benefits Tool, 2020).

The most well-substantiated quantitative association between green space and a single health outcome is for a reduction in all-cause mortality, with three recent meta-analysis studies quantifying this effect. Gascon et al. (2016) reported that a $10 \%$ increase in green space led to a significant reduction in cardiovascular mortality risk. Twohig-Bennett and Jones (2018) found statistically significant reductions in the incidence of Type II Diabetes, cardiovascular mortality, preterm births, diastolic blood pressure, and stress associated with increased greenspace exposure. More recently, Rojas-Rueda et al. (2019) reported that, per 0.1 increment of NDVI within a buffer of $500 \mathrm{~m}$ of a participant's home, there was a $4 \%$ lower risk of all-cause mortality. Local studies also show potential relationships between lack of green space and other health outcomes. In both Hermosillo, Mexico (Lara-Valencia et al., 2012), and Lyon, France, researchers found an association between high infant mortality areas and built environment factors, while in a nationwide study in the U.S., researchers found strong associations between women living in the lowest quantile of satellite-measured greenness and respiratory and cancer mortality (James et al., 2016). Due in great part to the limited number of studies and the heterogeneity of existing ones, the relationship between green space and mental health outcomes (Gascon et al., 2015) and social health determinants (Kabisch et al., 2016) are currently less consistent and need further research. A pilot study on exposure to green and blue spaces in Plovdiv, Bulgaria, recently found that NDVI and blue space was correlated with better mental health in 109 university students, but the effects of physical activity and restorative quality as important mediators requires further research (Dzhambov, 2018). Recent evidence from a metaanalysis by Georgiou et al. (2021) demonstrates that blue space-visible surface water such as coastal water and lakeshas similar salutogenic effects to green space in urban settings. Since water surfaces produce negative NDVI values, care must be taken in interpreting NDVI values for cities where both blue (negative NDVI) and green (positive NDVI) spaces are included within a single parcel, to avoid underestimation of the positive effects of exposure on health (Georgiou et al., 2021). Further research is needed to understand the mechanisms by which blue space, separate from green space, improves health.
Expansion of, and improved accessibility to, urban green space can be especially beneficial among marginalized or economically disadvantaged groups (Twohig-Bennett and Jones, 2018; Kruize et al., 2019). Elderly residents (Burkart et al., 2016; Heaviside et al., 2017), children (Engemann et al., 2019), and pregnant women (McEachan et al., 2016) also may experience greater benefits. While highly justified on both carbon mitigation and health promotion grounds, concerns have been raised that green space expansion could result in increased property values and displacement of marginalized residents that stood to gain the greatest benefits-a process known as green gentrification (Wolch et al., 2014; Cole et al., 2019). However, the health benefits of green space can be inclusive and reduce health inequity with proper foresight, regulation, and community buy-in (Lõhmus and Balbus, 2015; Nesbitt et al., 2018). A number of studies suggest evidence-based recommendations for policy planning with equity as the central focus to prevent the inadvertent impact that green space can have on gentrification (Cole et al., 2019; Bockarjova et al., 2020; C40 Cities and World Resources Institute, n.d).

\section{Physical Activity}

Fossil-fuel based on-road transportation contributes substantially to urban GHG emissions in most cities, representing over $30 \%$ of total GHG emissions in many top-emitting cities globally (Wei et al., 2021). Strategies to reduce vehicle miles traveled by investing in public transportation and/or bicycle and pedestrian infrastructure are often key components of urban climate action plans. A recent study found that active travel decreases mobility-related life cycle $\mathrm{CO}_{2}$ emissions, meaning there is a high potential to decrease emissions (Brand et al., 2021). Such actions bring associated health benefits not only through cleaner air but also by promoting physical activity. Inadequate physical inactivity is among the leading causes of death worldwide (Kohl, 2012), and the proportion of the population with sedentary or inactive lifestyles is increasing in many parts of the world. In China, for example, the number of sedentary residents has grown continuously due to rapid expansion of urbanization; more than $80 \%$ of Chinese residents lack physical activity (Jiang et al., 2013).

Although the mechanisms by which physical activity affects health (e.g., duration of activity, intensity, or pace) have not been fully understood, increasing physical activity for people who are minimally active is associated with substantial health benefits in both adults and children. Researchers have found strong evidence linking increased physical activity and reduced risk of breast cancer (Monninkhof et al., 2007) and colon cancer incidence (Wolin et al., 2009), cardiovascular disease mortality (Hamer and Chida, 2008), dementia (Hamer and Chida, 2009), type II diabetes incidence (Smith et al., 2016). Increased physical activity reduces the risk of all-cause mortality across a range of activity levels, but especially for physically inactive people who increase their activity levels (Woodcock et al., 2011; Kelly et al., 2014).

The relationships found through these multi-country meta-analyses has allowed researchers to draw dose-response relationships between physical activity and each health outcome. These dose-response relationships are important in order to 
quantify the potential health gains of increasing physical activity in populations with different levels of exercise, i.e., increasing physical activity for inactive people vs. for already active people. The resulting relative risks are increasingly being incorporated into local and national studies, as well as in recently developed tools that allow cities to assess the health gains from increased physical activity at the population level.

Besides meta-analysis, other studies have assessed the health benefits resulting from changes in physical activity in specific population groups. Assessing public and active transport users (compared to private transport users), resulted both significantly and independently predictive of lower body mass index (BMI) and percentage body fat for both men and women in the United Kingdom (Flint et al., 2014). In school-aged children and adolescents, studies have found greater health benefits (e.g., reduced risk of obesity and increased bone mineral density) with vigorous intensity activity and aerobic-based activities (Janssen and LeBlanc, 2010), better sleep quality with moderate-tovigorous physical activity (Negele et al., 2020), and increased cardiovascular fitness with changes from non-cycling to cycling to school (Cooper et al., 2008). For people with chronic obstructive pulmonary disease (COPD), moderate and high levels of physical activity resulted in lower risks of COPD hospital admissions, as well as respiratory and all-cause mortality in a group from Copenhagen, Denmark (Garcia-Aymerich et al., 2006). Given the growing evidence of the multiple physical and mental health benefits of increased physical activity in recent years, the WHO recommends people across all age groups get 150 $\mathrm{min} /$ week of moderate-intensity activity. The WHO also stated the benefits of being physically active outweigh the harms in its guidelines (Global Recommendations on Physical Activity for Health, 2010).

Recent studies have applied HIA methods to quantify the potential health benefits of interventions to increase physical activity. For example, Raifman et al. (2021) used the WHO HEAT tool (https://www.heatwalkingcycling.org) to project substantial reductions in all-cause mortality across states in the Northeastern US under a series of low carbon transportation scenarios that promoted increased investment in cycling and pedestrian infrastructure (Raifman et al., 2021). In London, Symonds et al. (2021) used the newly-developed CRAFT tool to estimate health benefits of low carbon interventions proposed by the London Mayor's office, estimating that around 1,900 deaths could be avoided due to cleaner air and increased physical activity, with nearly $90 \%$ of the avoided deaths coming from active transport. Other widely used tools for assessing health benefits of active transport are the ITHIM tool (Woodcock et al., 2009), which provides more granular assessments of both morbidity and mortality benefits, and the C40 Cities Walking and Cycling Benefits Tool that focuses on the health and associated economic benefits of increased physical activity in cities (C40 Cities, 2018). Note however that the pathways leading from infrastructure investments to changes in physical activity are complex (i.e., depending on a number of factors such as quality of space, safety, and cultural norms), and so one key challenge of an HIA is to predict the actual changes in physical activity accurately.
Nieuwenhuijsen and Khreis (2016) found that urban plans to become partly car free can reduce both traffic-related air pollution, as well as noise and temperature in city centers, and provide opportunities to increase green space and access to it. However, some studies suggest that transit-oriented development can create gentrification in cities depending on local dynamics and policies, as well as built environment attributes, which results in the displacement of already vulnerable groups (Padeiro et al., 2019). Researchers caution that potential detrimental effects from rerouting car traffic may exacerbate inequities in socioeconomically disadvantaged populations. Around Europe, over 250 cities have created Low Emission Zones (LEZ) (ULEZ, 2019). Eleven years after launching the LEZ in London, the city further implemented tighter restrictions in central London creating the world's first Ultra Low Emission Zone (ULEZ) in April 2019 with the goal to reduce the number of older, more polluting vehicles (Greater London Authority, 2019). From an equity standpoint, the ULEZ provides discounts and exemptions for disadvantaged community members, such as disabled people, as well as for service workers (C40 Cities and World Resources Institute, n.d). The city created a fund of over $\$ 60$ million to help vulnerable populations switch to less-polluting vehicles and now reinvests revenue from charging policies into the city's public transport system, as well as in promoting walking and cycling for transport (WRI, n.d.). Without these actions, the ULEZ could contribute to segregation and displacement of groups that otherwise would not be able to afford to live or work in close proximity to the ULEZ. To achieve environmental health justice goals, cities, and planning must prioritize equity in their climate mitigation plans and design their programs with proper foresight for the social and economic effects of policies.

\section{Noise}

The WHO Environmental Noise Guidelines for the European Region has compiled evidence and recommendations to reduce noise exposure as well as health outcomes based on systematic reviews (Jarosińska et al., 2018) and has found that prolonged exposure to environmental noise is associated with increased risk to both physiological and psychological health outcomes (WHO Regional Office for Europe, 2018). The main sources of urban noise pollution are related to traffic, including air, road, rail and ship traffic, as well as to residential, industrial, and/or occupational activities (Beutel et al., 2016). The European Environment Agency estimates environmental noise from road, rail, aircraft, and industry sources impacts at least $20 \%$ of the European Union population annually, causing detrimental impacts on public health. Noise pollution is projected to increase as urban growth and mobility demand continue (European Environment Agency, 2020).

Research has found that traffic noise exposure may be associated with negative health outcomes in cities ranging from Toronto in Canada (Shin et al., 2020), to Groningen in the Netherlands (de Kluizenaar et al., 2007), and Karachi in Pakistan (Siddiqui et al., 2015). Noise-induced hearing loss (NIHL) is common in both developed and developing nations. Noise pollution is a risk factor for annoyance and sleep disturbance (Theakston et al., 2011). Despite the sometimes 
existing heterogeneity in the age and sex of population groups studied, meta-analyses support the quantifiable association between increases in average noise levels and increased risk of hypertension (van Kempen and Babisch, 2012), coronary heart disease (Babisch, 2014), and stroke (Dzhambov and Dimitrova, 2016). Additional literature supports evidence of associations between changes in noise pollution and increased incidence of myocardial infarction (Babisch et al., 2005), diabetes incidence (Sørensen et al., 2013), all-cause mortality (Halonen et al., 2015; Dzhambov and Dimitrova, 2016), and major adverse cardiovascular disease events (MACE) (Osborne et al., 2020).

The US EPA (1974) and the WHO (Berglund et al., 1999) recommend a 24-h equivalent continuous average level [ $\left.\mathrm{L}_{\mathrm{EQ}(24)}\right]$ noise exposure limit of 70 A-weighted decibels (dBA), even though some non-auditory effects of noise, such as annoyance and reduced quality of life, can occur at $\mathrm{L}_{\mathrm{EQ}(24)}$ levels below $70 \mathrm{dBA}$ and are very prevalent (Basner et al., 2014). In the U.S. an estimated 104 million individuals had annual $\mathrm{L}_{\mathrm{EQ}(24)}$ higher than $70 \mathrm{dBA}$ in 2013, putting them at risk for NIHL, tinnitus, and other noise-related health consequences (Hammer et al., 2014). In six European countries, traffic noise is estimated to be the second leading environmental risk factor after $\mathrm{PM}_{2.5}$ pollution (Hänninen et al., 2014). Although some epidemiologic studies highlight the potential confounding effect of air pollution on noise pollution, especially in cardiovascular risk and road traffic noise studies, the effects of noise pollution have been demonstrated in scenarios where air pollutants are not a factor, which supports the claim that noise pollution has independent health effects (Kalsch et al., 2014; Munzel et al., 2014).

Certain population groups are more vulnerable to the effects of noise pollution. Children are at risk of presenting processing and language developmental challenges related to reading and memory (Berglund et al., 1999). Additionally, noise pollution is also an environmental justice issue. In 2014, a case study in Birmingham found its black population experienced the highest median combined daytime rail/road/airport estimated noise levels among all ethnic groups (Brainard et al., 2004). A recent study in Boston by Lee (2021) reported that spatial and sociodemographic characteristics influence perceived loudness. Similarly, Walker et al. (2021) demonstrated the linkage between noise exposure and environmental justice and the importance of exposure assessments in vulnerable communities.

Several studies have assessed the health benefits of reducing noise pollution both directly and indirectly. For instance, reductions in motorized traffic achieved by switching to zeroand low-emitting transportation modes, such as public and active transportation, and improvements in urban green space availability and green infrastructure, may reduce both noise and air pollution (Mueller et al., 2017). Green space availability improves vegetation coverage, which may function as a natural sound barrier (Van Renterghem et al., 2015) and can simultaneously reduce heat through shading and evapotranspiration cooling of water (Raji et al., 2015). Initiatives that increase physical activity through improved active transportation options can simultaneously mitigate noise pollution, thus doubling the health benefits in a population (Woodcock et al., 2011; Mueller et al., 2017). Noise pollution can further be mitigated through climate actions implemented in buildings directly, as well as indirectly through the reduced traffic and traffic-related air pollution buildings may incentivize, such as through sustainable building designs that incentivize minimized acoustic levels (U. S. Green Building Council, 2019) and Urban Consolidation Centers, which consolidate goods for transport to their final destination and commonly use electric vehicles (Allen et al., 2012, 2014; van Heeswijk et al., 2019).

\section{Summary and Synthesis}

Table 1 summarizes the evidence for health outcomes associated with the four pathways above. The first category represents exposure-outcome pairs with associations that are fully supported by multi-country meta-analysis. The compilation of these epidemiological studies have enabled researchers to quantify the exposure-outcome relationships through relative risks and confidence intervals. Thus, these relationships are increasingly being incorporated into local and national HIAs, as well as into newly developed tools that help decision makers more easily quantify the health benefits of climate mitigation actions (e.g., Pathways-AQ, LEAP-IBC). The second category shows exposure-outcome pairs that have been studied in limited geographical areas or population groups and do not result in quantifiable relationships. Thus, more rigorous studies are still needed to identify these associations and causality.

Cardiovascular diseases and all-cause mortality are the health outcomes that have been most extensively studied in relation to the four pathways. Air pollution has been extensively included in regional and global studies, particularly in relation to all-cause mortality, mortality from cardiorespiratory diseases, COPD, lung cancer, and asthma morbidity (i.e., exacerbation and hospitalizations). Increasing evidence supports associations between air pollutants and cognitive decline, dementia, depression, and diabetes. For green space, several meta-analyses of epidemiological studies from many countries support associations with all-cause and cardiovascular mortality, diastolic blood pressure, pre-term births, stress, and diabetes. Additional evidence is building for associations with infant mortality, mental health, cancer mortality and social health determinants such as viso-motoric development. Noise has been linked in epidemiological meta-analyses with hypertension, coronary heart disease, and stroke. Studies with more limited geographies also indicate associations with myocardial infarction, diabetes, all-cause mortality, and cardiovascular disease in general. For physical activity, metaanalyses of epidemiological evidence indicate associations with breast cancer, cardiovascular disease, dementia, colon cancer, all-cause mortality, and diabetes, with additional evidence building for associations with hypertension, BMI, and other outcomes.

Due to the small sample size in some studies or the lack of full representation of population groups (e.g., studies that only include children, adults or elderly groups) and as the mixed methods used in exposure assessment studies (e.g., using tree cover vs. NDVI in green space studies), evidence 
TABLE 1 | Summary of the evidence for health outcomes associated with the four pathways reviewed in this paper, the direction of the association, and references for example meta-analyses.

\begin{tabular}{|c|c|c|c|c|}
\hline \multirow[t]{2}{*}{ Epidemiologic literature } & \multicolumn{4}{|c|}{ Exposure pathways } \\
\hline & Decreased air pollution & Increased green space & $\begin{array}{l}\text { Decreased noise } \\
\text { pollution }\end{array}$ & $\begin{array}{l}\text { Increased physical } \\
\text { activity }\end{array}$ \\
\hline \multirow[t]{9}{*}{$\begin{array}{l}\text { Associations are fully } \\
\text { supported by multi-country } \\
\text { meta-analysis (readily }\end{array}$} & $\begin{array}{l}\downarrow \text { Asthma incidence, ED } \\
\text { visits (Khreis et al., 2017) }\end{array}$ & $\begin{array}{l}\downarrow \text { Cardiovascular mortality } \\
\text { (Gascon et al., 2016) }\end{array}$ & $\begin{array}{l}\downarrow \text { Hypertension (van } \\
\text { Kempen and Babisch, } \\
\text { 2012) }\end{array}$ & $\begin{array}{l}\downarrow \text { Breast cancer } \\
\text { (Monninkhof et al., 2007) }\end{array}$ \\
\hline & $\begin{array}{l}\downarrow \text { Asthma exacerbation } \\
\text { (Orellano et al., 2017) }\end{array}$ & $\begin{array}{l}\downarrow \text { Diastolic blood pressure } \\
\text { (Twohig-Bennett and Jones, } \\
2018 \text { ) }\end{array}$ & $\begin{array}{l}\downarrow \text { Coronary heart disease } \\
\text { (Burnett et al., 2018) }\end{array}$ & $\begin{array}{l}\downarrow \text { Cardiovascular disease } \\
\text { (Hamer and Chida, 2008) }\end{array}$ \\
\hline & $\begin{array}{l}\downarrow \text { All-cause mortality } \\
\text { (Burnett et al., 2018) }\end{array}$ & $\begin{array}{l}\downarrow \text { Preterm births } \\
\text { (Twohig-Bennett and Jones, } \\
2018 \text { ) }\end{array}$ & $\begin{array}{l}\downarrow \text { Stroke (Dzhambov and } \\
\text { Dimitrova, 2016) }\end{array}$ & $\begin{array}{l}\downarrow \text { Dementia (Hamer and } \\
\text { Chida, 2009) }\end{array}$ \\
\hline & $\begin{array}{l}\downarrow \text { Preterm birth/low birth } \\
\text { weight (GBD } 2019 \text { Risk } \\
\text { Factors Collaborators, } \\
\text { 2020) }\end{array}$ & $\begin{array}{l}\downarrow \text { Stress (salivary cortisol; } \\
\text { heart rate) (Twohig-Bennett } \\
\text { and Jones, 2018) }\end{array}$ & & $\begin{array}{l}\downarrow \text { Colon cancer (Wolin et al., } \\
2009)\end{array}$ \\
\hline & $\begin{array}{l}\downarrow \text { Diabetes incidence (GBD } \\
2019 \text { Risk Factors } \\
\text { Collaborators, 2020) }\end{array}$ & $\begin{array}{l}\downarrow \text { Diabetes incidence } \\
\text { (Twohig-Bennett and Jones, } \\
2018 \text { ) }\end{array}$ & & $\begin{array}{l}\downarrow \text { All-cause mortality } \\
\text { (Woodcock et al., 2011) }\end{array}$ \\
\hline & $\begin{array}{l}\downarrow \text { Respiratory mortality } \\
\text { (GBD } 2019 \text { Risk Factors } \\
\text { Collaborators, 2020) }\end{array}$ & $\begin{array}{l}\downarrow \text { All-cause mortality } \\
\text { (Rojas-Rueda et al., 2019) }\end{array}$ & & $\begin{array}{l}\downarrow \text { Diabetes incidence (Smith } \\
\text { et al., 2016) }\end{array}$ \\
\hline & $\begin{array}{l}\downarrow \text { Lung cancer (GBD } 2019 \\
\text { Risk Factors Collaborators, } \\
\text { 2020) }\end{array}$ & & & \\
\hline & $\begin{array}{l}\downarrow \text { Cardiovascular mortality } \\
\text { (GBD } 2019 \text { Risk Factors } \\
\text { Collaborators, 2020) }\end{array}$ & & & \\
\hline & $\begin{array}{l}\downarrow \text { Chronic obstructive } \\
\text { pulmonary disease (COPD) } \\
\text { (GBD } 2019 \text { Risk Factors } \\
\text { Collaborators, 2020) }\end{array}$ & & & \\
\hline \multirow{2}{*}{$\begin{array}{l}\text { Associations are partially } \\
\text { supported by evidence from } \\
\text { limited geographies } \\
\text { (quantifiable in exploratory } \\
\text { analyses) }\end{array}$} & $\begin{array}{l}\downarrow \text { Cognitive decline (Zhang } \\
\text { et al., 2018) }\end{array}$ & $\begin{array}{l}\downarrow \text { Infant mortality } \\
\text { (Lara-Valencia et al., 2012) }\end{array}$ & $\begin{array}{l}\downarrow \text { Myocardial infarction } \\
\text { (Babisch et al., 2005) }\end{array}$ & $\begin{array}{l}\downarrow \text { Respiratory mortality } \\
\text { (Garcia-Aymerich et al., } \\
\text { 2006) }\end{array}$ \\
\hline & $\begin{array}{l}\downarrow \text { Dementia (Peters et al., } \\
2019) \\
\downarrow \text { Depression (Fan et al., } \\
2020 \text { ) }\end{array}$ & $\begin{array}{l}\uparrow \text { Improved mental health } \\
\text { (Gascon et al., 2015) } \\
\downarrow \text { Cancer mortality (James } \\
\text { et al., 2016) }\end{array}$ & $\begin{array}{l}\downarrow \text { Diabetes incidence } \\
\text { (Sørensen et al., 2013) } \\
\downarrow \text { All-cause mortality } \\
\text { (Halonen et al., 2015) }\end{array}$ & $\begin{array}{l}\uparrow \text { Cardio-respiratory fitness } \\
\text { (Cooper et al., 2008) } \\
\downarrow \text { Body mass index (BMI) } \\
\text { (Flint et al., 2014) }\end{array}$ \\
\hline
\end{tabular}

Colors indicate the general strength of the evidence, as described in the first column.

is still insufficient to draw strong conclusions from some exposure-outcome pairs. However, considering the evidence in full, reduced cases of mortality and disease associated with changes in these four exposure pathways are currently quantifiable for many health outcomes. As the epidemiological literature evolves and evidence builds, quantifying additional health outcomes associated with these exposure pathways will likely be possible. Health impact assessments should evolve with the epidemiological literature, and integrate exposureoutcome pairs as the evidence supporting their association solidifies. Doing so will enable HIAs to account for the health benefits of improved environmental quality as comprehensively as possible.

\section{ASSESSING THE HEALTH CO-BENEFITS OF CLIMATE MITIGATION ACTIONS IN CITIES: THE C40 CITIES EXPERIENCE}

Health impact assessments and burden of disease estimates have been performed mostly at the global or regional, rather than national or local levels (GBD 2019 Risk Factors Collaborators, 2020). This tendency contributes to the gap in local-scale information for city- or country-specific policy making, particularly in low- and middle-income countries (LMICs). Similarly, the complexity of cities and forces that contribute to urban inequities makes it difficult to develop indicators. Specifically, measures that are directly related to local 
needs, and that can integrate science, policy and community, can help to achieve greater urban health equity (Corburn and Cohen, 2012). Examples of practices that may aid in bridging the gaps between complex urban places and health equity include community-led mapping, health equity in all urban policies (or Health in all Policies-HiAP), urban ecosystem services approaches, and integrated participatory slum upgrading (Corburn, 2017).

Here, we describe the experience of C40 Cities, one of the largest global city networks, in integrating co-benefits assessments into urban climate action planning. The C40 Cities group, which is now in its sixteenth year and works with some of the largest and most influential global cities, has the mission to halve, over the course of a decade, the collective carbon emissions of its member cities while also improving resilience and equity in each city (C40 Cities, 2021b). C40 Cities has created a guide with resources for cities to tackle climate change and inequities jointly. The guide makes climate action recommendations and provides resources to support cities in advancing inclusive engagement and planning processes; these resources can help advance the goal of the impact of policies being inclusively and equitably distributed (C40 Cities and World Resources Institute, n.d.). While approaches utilized by $\mathrm{C} 40$ and partner cities have uncertainties, this experience demonstrates how cities are increasingly considering the multiple societal, environmental, and health benefits of municipal actions undertaken to reduce GHG emissions.

During the last decade, the C40 Cities Benefits Research Programme has provided technical assistance to over 50 cities across the globe. In making the case for climate action with tangible, short-term benefits on health and well-being, equity, economy, and security, cities have implemented climate-health mitigation initiatives focused on a range of environmental exposures. The most commonly tackled environmental exposure pathway to date is air quality. With GHG mitigation actions in the transport, building, and industry sectors, cities are tackling air pollution simultaneously and accruing health benefits. In other words, cities are reducing GHG emissions, $\mathrm{PM}_{2.5}$ levels and premature deaths at the same time. Proposed mitigation actions include vehicle electrification, creation of low-emission zones, building retrofits, and reducing industrial emissions. Results from high-impact actions taken to reduce $\mathrm{PM}_{2.5}$ levels across 25 global cities show that 2,655 total deaths and 9,275 annual hospitalizations could be prevented, while also reducing asthma cases, increasing physical activity, and improving well-being across all cities (C40 Cities et al., n.d).

The C40 Benefits of Urban Climate Action tool, Walking and Cycling tool, and Impact Framework are available on demand from the C40 Benefits Research Team (https://www.c40.org/ benefits). The widely used ITHIM (and the recently developed ITHIM-Global), WHO HEAT, USEPA BenMAP, AirQ+, and LEAP-IBC tools described above are publicly available. The most recent HIA of changes in travel patterns using the ITHIMGlobal model was performed in Accra, Ghana. In addition to air pollution and physical activity, it also assesses traffic injuries. The study found that replacing long car and taxi trips with bus trips is the most beneficial scenario for health, i.e., a scenario that includes introducing policy actions to improve public transportation along with measures to increase public transport accessibility averts over 600 premature deaths every year (Garcia et al., 2021). Some city-specific, ongoing efforts in the transportation sector supported by C40 Cities include Cape Town's Transit Oriented Development Strategic Framework (TODSF). The TODSF aims to make transport the foundation of the city's long-term land-use and development plans. By prioritizing the reduction of travel distances and costs and optimizing land-use to prevent urban sprawl, Cape Town will greatly improve its air quality and may reduce health consequences associated with car traffic noise (C40 Cities Climate Leadership Group, 2016). Similarly, Auckland established a City Centre Cycle Network program, which aims to make cycling the transportation method of choice for Aucklanders by building new cycleways. Climate-health benefits of this program include reductions in air, noise, and water pollution as well as increased physical activity (C40 Cities Climate Leadership Group, 2017).

\section{FUTURE RESEARCH NEEDS}

As reviewed above, robust evidence now exists on health benefits for four key pathways relevant to climate mitigation actions in cities. This evidence base provides a useful tool box for cities that wish to take health benefits into account in prioritizing climate mitigation actions. However, further research is needed to address limitations in the available evidence. For example, heterogeneity in results for green space derives in part from the different exposure definitions. Standardization of methods will help support larger and more robust meta-analyses, as well as providing locally- or regionally-relevant findings. Other challenges in meta-analyses include the varying age groups used (e.g., all ages, adults or elderly) and the sometimes different duration of residency/exposure of participants that are included in studies that assess long-term exposure to risk factors, as well as the confounding factors that are taken into account in the studies. Similarly, local-scale air quality studies have identified a gap in, and the need for, high resolution data for both pollutant concentrations and baseline disease rates to identify intra-city inequities in attributable health risks (Castillo et al., 2021; Southerland et al., 2021). This high-resolution data also helps engage communities, as well as understand local exposure to pollutants, pollution sources, and vulnerability to exposure (e.g., Johnston et al., 2019), while it helps ensure continued community involvement and health improvements even after funding and studies are finalized (English et al., 2017). Although air quality has been extensively studied globally, systematic reviews and meta-analyses for physical activity, green space, and noise exposures are supported by fewer studies. In particular, although evidence suggests that increased green space and decreased noise pollution would lead to better health outcomes, further research, and consistent studies are needed to infer causal associations between these pathways and specific health outcomes. 
One challenge to effective action is that evidence from highincome countries may not be directly transferable into applicable policies in LMICs where urban environments differ greatly. The lack of a strong body of literature on greenness in LMICs, where access to green and blue urban spaces may be limited, implies that research to-date does not reflect the reality of a large proportion of the world's population. Country-specific data and research on the built environment, social behaviors, and health outcomes are needed in order to understand the potential success of climate and health interventions. For example, most research on green space has been done in the Global North. Recently, researchers found that among 11 cities in 10 countries from Central and South America, neighborhood formality and related built environment characteristics are associated with park use, but observed a lack of association between perceived social disorder (e.g., presence of gangs, crime) and park use, which has been noted in previous studies, mostly from the Global North, to be a barrier to park use (Moran et al., 2020). Cultural norms, traditions, and perception of what is right and wrong in public spaces varies greatly between countries, creating regional knowledge gaps. In order to create cities that promote health and well-being while avoiding widening health inequities in LMICs, integrated planning and optimization of existing resources, as well as evaluations before and after implementation are needed (Giles-Corti et al., 2016).

In addition to knowledge gaps, translating emerging knowledge into policy-making remains a challenge. City powers over given sectors vary greatly between cities, shaping what the city can accomplish on its own in terms of environmental risk reductions, and making the case for vertical integration-the need for collaboration with surrounding localities and crossjurisdictional agencies. A review of 29 climate action plans in major U.S. cities found that many plans lack the breadth and cohesiveness needed to achieve significant GHG reductions and climate change mitigation (Deetjen et al., 2018). Policies are likely to be most effective when they are developed by multidisciplinary teams that include policy makers, researchers, and representatives from affected communities. To improve research translation and ultimately benefit communities, a system that rewards policy-relevant research and communication is also necessary (Giles-Corti et al., 2015). In communities that have suffered from environmental justice issues, the coproduction of science policies, where local knowledge is taken into consideration in the decision-making process, could be a hopeful framework to include relevant, fine-scale knowledge (Corburn, 2007).

Finally, while we have focused mainly on health benefit pathways, it must be acknowledged that health "dis-benefits" are also possible as we transition to a low carbon future. For example, policies that increase bike and pedestrian mobility can lead to more traffic fatalities and higher air pollution exposures for people engaged in outdoor physical activity. Greening of cities can bring many benefits, but may also raise concerns about gentrification and pushing out low-income residents. Across all low-carbon interventions, it is important to take account of current environmental health disparities and to ensure that interventions are designed to alleviate them to the extent possible.

\section{CONCLUSION}

As cities identify and implement policies to achieve carbon emission reductions consistent with climate targets, quantitative estimates of the local health benefits that flow from these policies can provide essential information to policy makers engaged in weighing benefits against costs, prioritizing actions that are most cost-effective in achieving health benefits for a given degree of carbon reduction, and evaluating other policy-related outcomes such as improved environmental equity. Our review confirms that air quality improvements are likely to represent an important pathway to health benefits. In addition, the evidence to support quantitative health benefit assessments for other environmental health pathways that are sensitive to climate action is building, including for physical activity, green space, and noise. All of these environmental health pathways are supported by wellconducted epidemiological studies in multiple locales, providing quantitative exposure-response data that can be used as inputs to HIAs. Going forward, the challenge for integrating quantitative health benefits assessments into urban climate action plans will be less about lack of evidence, and more about limited knowledge of these benefits outside of the academic community, and limited capacity and resources to undertake these assessments. Still, efforts are needed to strengthen the evidence base for all of these pathways in LMIC cities, where data limitations have so far hindered efforts to carry out needed research. Progress can be driven forward by creating partnerships that involve multiple government sectors (including health, environment, transportation, energy) along with academics and representatives from affected communities to address the complex challenges of achieving both climate and public health benefits in cities around the world.

\section{AUTHOR CONTRIBUTIONS}

$\mathrm{SA}, \mathrm{MC}$, and $\mathrm{PK}$ contributed to the conception and design of the study. SA, MC, LJ, PK, MM, MN, NP, and YS wrote sections of the manuscript, including figures, and the table. $\mathrm{ZC}, \mathrm{RH}, \mathrm{IK}$, JM, SN, and $\mathrm{HB}$ contributed to drafts of the manuscript. All authors contributed to revisions of the text and figures of the final manuscript.

\section{FUNDING}

This work was supported by Wellcome Trust (216075/Z/19/Z).

\section{ACKNOWLEDGMENTS}

This paper was supported by Wellcome Trust grant number 216075/Z/19/Z. We appreciate helpful discussions with the broader Climate Action Planning-Air Quality team supported by that grant. 


\section{REFERENCES}

Achakulwisut, P., Brauer, M., Hystad, P., and Anenberg, S. C. (2019). Global, national, and urban burdens of paediatric asthma incidence attributable to ambient $\mathrm{NO}_{2}$ pollution: estimates from global datasets. Lancet Planet. Health 3, e166-e178. doi: 10.1016/S2542-5196(19)30046-4

Allen, J., Browne, M., Woodburn, A., and Leonardi, J. (2012). The role of urban consolidation centres in sustainable freight transport. Transp. Rev. 32, 473-490. doi: 10.1080/01441647.2012.688074

Allen, J., Browne, M., Woodburn, A., and Leonardi, J. (2014). A review of urban consolidation centres in the supply chain based on a case study approach. Supply Chain Forum Int. J. 15, 100-112. doi: 10.1080/16258312.2014.11517361

Anenberg, S. C., Achakulwisut, P., Brauer, M., Moran, D., Apte, J. S., and Henze, D. K. (2019). Particulate matter-attributable mortality and relationships with carbon dioxide in 250 urban areas worldwide. Sci. Rep. 9, 11552. doi: 10.1038/s41598-019-48057-9

Anenberg, S. C., Belova, A., Brandt, J., Fann, N., Greco, S., Guttikunda, S., et al. (2016). Survey of ambient air pollution health risk assessment tools: survey of ambient air pollution health risk assessment tools. Risk Anal. 36, 1718-1736. doi: $10.1111 /$ risa. 12540

Anenberg, S. C., Schwartz, J., Shindell, D., Amann, M., Faluvegi, G., Klimont, Z., et al. (2012). Global air quality and health co-benefits of mitigating near-term climate change through methane and black carbon emission controls. Environ. Health Perspect. 120, 831-839. doi: 10.1289/ehp.1104301

Apte, J. S., Marshall, J. D., Cohen, A. J., and Brauer, M. (2015). Addressing global mortality from ambient PM 2.5. Environ. Sci. Technol. 49, 8057-8066. doi: 10.1021/acs.est.5b01236

Babisch, W. (2014). Updated exposure-response relationship between road traffic noise and coronary heart diseases: a meta-analysis. Noise Health 16, 1. doi: $10.4103 / 1463-1741.127847$

Babisch, W., Beule, B., Schust, M., Kersten, N., and Ising, H. (2005). Traffic noise and risk of myocardial infarction. Epidemiology 16, 33-40. doi: 10.1097/01.ede.0000147104.84424.24

Basara, J. B., Basara, H. G., Illston, B. G., and Crawford, K. C. (2010). The impact of the urban heat island during an intense heat wave in Oklahoma City. Adv. Meteorol. 2010, 230365. doi: 10.1155/2010/230365

Basner, M., Babisch, W., Davis, A., Brink, M., Clark, C., Janssen, S., et al. (2014). Auditory and non-auditory effects of noise on health. Lancet 383, 1325-1332. doi: 10.1016/S0140-6736(13)61613-X

Berglund, B., Lindvall, T., and Schwela, D. H., (1999). Guidelines for Community Noise. Geneva: World Health Organization.

Beutel, M. E., Jünger, C., Klein, E. M., Wild, P., Lackner, K., Blettner, M., et al. (2016). Noise annoyance is associated with depression and anxiety in the general population- the contribution of aircraft noise. PLoS ONE 11, e0155357. doi: 10.1371/journal.pone.0155357

Bockarjova, M., Botzen, W. J. W., van Schie, M. H., and Koetse, M. J. (2020). Property price effects of green interventions in cities: a metaanalysis and implications for gentrification. Environ. Sci. Policy 112, 293-304. doi: 10.1016/j.envsci.2020.06.024

Brainard, J. S., Jones, A. P., Bateman, I. J., and Lovett, A. A. (2004). Exposure to environmental urban noise pollution in Birmingham, UK. Urban Stud. 41, 2581-2600. doi: 10.1080/0042098042000294574

Brand, C., Dons, E., Anaya-Boig, E., Avila-Palencia, I., Clark, A., de Nazelle, A., et al. (2021). The climate change mitigation effects of daily active travel in cities. Transp. Res. Part Transp. Environ. 93, 102764. doi: 10.1016/j.trd.2021.1 02764

Burkart, K., Meier, F., Schneider, A., Breitner, S., Canário, P., Alcoforado, M. J., et al. (2016). Modification of heat-related mortality in an elderly urban population by vegetation (urban green) and proximity to water (urban blue): evidence from Lisbon, Portugal. Environ. Health Perspect. 124, 927-934. doi: 10.1289/ehp.1409529

Burnett, R., Chen, H., Szyszkowicz, M., Fann, N., Hubbell, B., Pope, C. A., et al. (2018). Global estimates of mortality associated with long-term exposure to outdoor fine particulate matter. Proc. Natl. Acad. Sci. U.S.A. 115, 9592-9597. doi: 10.1073/pnas.1803222115

C40 Cities Climate Leadership Group (2016). Cities 100 2016: 100 Solutions for Climate Action in Cities. London. Available online at: https://issuu.com/ sustainia/docs/cities1002016finalsmall (accessed October 28, 2021).
C40 Cities Climate Leadership Group (2017). Cities 100 2017: 100 Solutions for Climate Action in Cities. London. Available online at: https://issuu.com/ sustainia/docs/cities1002017 (accessed October 28, 2021).

C40 Cities, Johnson and Johnson, and Burohappold Engineering. (n.d.). Toward a Healthier World. Available online at: https://www.c40.org/researches/towarda-healthier-world

C40 Cities and World Resources Institute. (n.d.). Inclusive Planning Executive Guidance: How to Tackle Climate Change and Inequality Jointly: Practical Resources and Guidance for Cities. Available online at: https://c40.my.salesforce.com/sfc/p/\#36000001Enhz/a/1Q000000MeUn/Z. dUPCWEfN9u60SMUmwn8WLox9H6Y4fAPILYHiTKD0s

C40 Cities. (2018). C40 Walking and Cycling Benefits Tool Methodology Report.

C40 Cities. (2021a). Climate Action Planning Guide [WWW Document]. Available online at: https://www.c40knowledgehub.org/s/guide-home? language $=$ en_USandutm_campaign $=\mathrm{CAP} \$+\$$ Guideandutm_medium $=\mathrm{Hub} \$+$ $\$$ Newsletterandutm_source $=$ Hub $\$+\$$ Newsletter\#article1 (accessed July 17, 2021).

C40 Cities. (2021b). C40 Annual Report 2020.

Castillo, M. D., Kinney, P., Southerland, V. A., Arno, C. A., Crawford, K., van Donkelaar, A., et al. (2021). Estimating Intra-Urban Inequities in PM2.5Attributable Health Impacts: A Case Study. Washington, DC: Public Health. doi: 10.1002/essoar.10506837.1

Chen, A., Yao, X. A., Sun, R., and Chen, L. (2014). Effect of urban green patterns on surface urban cool islands and its seasonal variations. Urban For. Urban Green. 13, 646-654. doi: 10.1016/j.ufug.2014.07.006

ClimateWorks Foundation and World Bank Group (2014). Climate-Smart Development : Adding Up the Benefits of Actions that Help Build Prosperity, End Poverty and Combat Climate Change.

Cohen, A. J., Brauer, M., Burnett, R., Anderson, H. R., Frostad, J., Estep, K., et al. (2017). Estimates and 25-year trends of the global burden of disease attributable to ambient air pollution: an analysis of data from the global burden of diseases study 2015. Lancet 389, 1907-1918. doi: 10.1016/S0140-6736(17)30505-6

Cole, H. V. S., Triguero-Mas, M., Connolly, J. J. T., and Anguelovski, I. (2019). Determining the health benefits of green space: does gentrification matter? Health Place 57, 1-11. doi: 10.1016/j.healthplace.2019.02.001

Colmer, J., Hardman, I., Shimshack, J., and Voorheis, J. (2020). Disparities in $\mathrm{PM}_{2.5}$ air pollution in the United States. Science 369, 575-578. doi: 10.1126/science.aaz9353

Cooper, A. R., Wedderkopp, N., Jago, R., Kristensen, P. L., Moller, N. C., Froberg, K., et al. (2008). Longitudinal associations of cycling to school with adolescent fitness. Prev. Med. 47, 324-328. doi: 10.1016/j.ypmed.2008.06.009

Corburn, J. (2007). Community knowledge in environmental health science: co-producing policy expertise. Environ. Sci. Policy 10, 150-161. doi: 10.1016/j.envsci.2006.09.004

Corburn, J. (2017). Urban place and health equity: critical issues and practices. Int. J. Environ. Res. Public Health 14, 117. doi: 10.3390/ijerph14020117

Corburn, J., and Cohen, A. K. (2012). Why we need urban health equity indicators: integrating science, policy, and community. PLoS Med. 9, e1001285. doi: 10.1371/journal.pmed.1001285

de Kluizenaar, Y., Gansevoort, R. T., Miedema, H. M. E., and de Jong, P. E. (2007). Hypertension and road traffic noise exposure. J. Occup. Environ. Med. 49, 484-492. doi: 10.1097/JOM.0b013e318058a9ff

Deetjen, T. A., Conger, J. P., Leibowicz, B. D., and Webber, M. E. (2018). Review of climate action plans in 29 major U.S. cities: comparing current policies to research recommendations. Sustain. Cities Soc. 41, 711-727. doi: $10.1016 /$ j.scs.2018.06.023

Dzhambov, A. M. (2018). Residential green and blue space associated with better mental health: a pilot follow-up study in university students. Arch. Ind. Hyg. Toxicol. 69, 340-349. doi: 10.2478/aiht-2018-69-3166

Dzhambov, A. M., and Dimitrova, D. D. (2016). Exposure-response relationship between traffic noise and the risk of stroke: a systematic review with metaanalysis. Arh. Hig. Rada Toksikol. 67, 136-151. doi: 10.1515/aiht-2016-67-2751

Dzhambov, A. M., Markevych, I., Tilov, B., Arabadzhiev, Z., Stoyanov, D., Gatseva, P., et al. (2018). Lower noise annoyance associated with GIS-derived greenspace: pathways through perceived greenspace and residential noise. Int. J. Environ. Res. Public Health 15, 1533. doi: 10.3390/ijerph15071533

Engemann, K., Pedersen, C. B., Arge, L., Tsirogiannis, C., Mortensen, P. B., and Svenning, J.-C. (2019). Residential green space in childhood is associated with 
lower risk of psychiatric disorders from adolescence into adulthood. Proc. Natl. Acad. Sci. U.S.A. 116, 5188-5193. doi: 10.1073/pnas.1807504116

English, P. B., Olmedo, L., Bejarano, E., Lugo, H., Murillo, E., Seto, E., et al. (2017). The imperial county community air monitoring network: a model for community-based environmental monitoring for public health action. Environ. Health Perspect. 125, 074501. doi: 10.1289/EHP1772

European Environment Agency (2020). Environmental Noise in Europe, 2020. Publications Office, LU.

Fan, S.-J., Heinrich, J., Bloom, M. S., Zhao, T.-Y., Shi, T.-X., Feng, W.R., et al. (2020). Ambient air pollution and depression: a systematic review with meta-analysis up to 2019. Sci. Total Environ. 701, 134721. doi: $10.1016 /$ j.scitotenv.2019.134721

Fann, N., Kim, S.-Y., Olives, C., and Sheppard, L. (2017). Estimated changes in life expectancy and adult mortality resulting from declining PM2.5 exposures in the contiguous United States: 1980-2010. Environ. Health Perspect. 125, 097003. doi: 10.1289/EHP507

Fann, N., Lamson, A. D., Anenberg, S. C., Wesson, K., Risley, D., and Hubbell, B. J. (2012). Estimating the national public health burden associated with exposure to ambient PM2.5 and ozone: U.S. public health burden of PM2.5 and ozone. Risk Anal. 32, 81-95. doi: 10.1111/j.1539-6924.2011.01630.x

Flint, E., Cummins, S., and Sacker, A. (2014). Associations between active commuting, body fat, and body mass index: population based, cross sectional study in the United Kingdom. BMJ 349, g4887. doi: 10.1136/bmj.g4887

Frumkin, H., Bratman, G. N., Breslow, S. J., Cochran, B., Kahn P. H. Jr., Lawler, J. J., et al. (2017). Nature contact and human health: a research agenda. Environ. Health Perspect. 125, 075001. doi: 10.1289/EHP1663

Garcia, L., Johnson, R., Johnson, A., Abbas, A., Goel, R., Tatah, L., et al. (2021). Health impacts of changes in travel patterns in Greater Accra Metropolitan Area, Ghana. Environ. Int. 155, 106680. doi: 10.1016/j.envint.2021.106680

Garcia-Aymerich, J., Lange, P., Benet, M., Schnohr, P., and Anto, J. M. (2006). Regular physical activity reduces hospital admission and mortality in chronic obstructive pulmonary disease: a population based cohort study. Thorax 61, 772-778. doi: 10.1136/thx.2006.060145

Gascon, M., Triguero-Mas, M., Martínez, D., Dadvand, P., Forns, J., Plasència, A., et al. (2015). Mental health benefits of long-term exposure to residential green and blue spaces: a systematic review. Int. J. Environ. Res. Public Health 12, 4354-4379. doi: 10.3390/ijerph120404354

Gascon, M., Triguero-Mas, M., Martínez, D., Dadvand, P., Rojas-Rueda, D., Plasència, A., et al. (2016). Residential green spaces and mortality: a systematic review. Environ. Int. 86, 60-67. doi: 10.1016/j.envint.2015.10.013

GBD 2019 Risk Factors Collaborators. (2020). Global burden of 87 risk factors in 204 countries and territories, 1990-2019: a systematic analysis for the global burden of disease study 2019. Lancet Lond. Engl. 396, 1223-1249. doi: 10.1016/S0140-6736(20)30752-2

Georgiou, M., Morison, G., Smith, N., Tieges, Z., and Chastin, S. (2021). Mechanisms of impact of blue spaces on human health: a systematic literature review and meta-analysis. Int. J. Environ. Res. Public Health 18, 2486. doi: 10.3390/ijerph18052486

Giles-Corti, B., Sallis, J. F., Sugiyama, T., Frank, L. D., Lowe, M., and Owen, N. (2015). Translating active living research into policy and practice: one important pathway to chronic disease prevention. J. Public Health Policy 36, 231-243. doi: 10.1057/jphp.2014.53

Giles-Corti, B., Vernez-Moudon, A., Reis, R., Turrell, G., Dannenberg, A. L., Badland, H., et al. (2016). City planning and population health: a global challenge. Lancet 388, 2912-2924. doi: 10.1016/S0140-6736(16)30066-6

Global Recommendations on Physical Activity for Health. (2010). WHO Guidelines Approved by the Guidelines Review Committee. Geneva: World Health Organization.

Greater London Authority. (2019). Central London Ultra Low Emission Zone - Six Month Report.

GreenUr (2021). The Green Urban Spaces and Health Tool [WWW Document]. Available online at: https://www.euro.who.int/en/health-topics/environmentand-health/urban-health/activities/greenur-the-green-urban-spaces-andhealth-tool (accessed December 5, 2021).

Hajat, A., Hsia, C., and O'Neill, M. S. (2015). Socioeconomic disparities and air pollution exposure: a global review. Curr. Environ. Health Rep. 2, 440-450. doi: 10.1007/s40572-015-0069-5
Halonen, J. I., Hansell, A. L., Gulliver, J., Morley, D., Blangiardo, M., Fecht, D., et al. (2015). Road traffic noise is associated with increased cardiovascular morbidity and mortality and all-cause mortality in London. Eur. Heart J. 36, 2653-2661. doi: 10.1093/eurheartj/ehv216

Hamer, M., and Chida, Y. (2008). Walking and primary prevention: a metaanalysis of prospective cohort studies. Br. J. Sports Med. 42, 238-243. doi: 10.1136/bjsm.2007.039974

Hamer, M., and Chida, Y. (2009). Physical activity and risk of neurodegenerative disease: a systematic review of prospective evidence. Psychol. Med. 39, 3-11. doi: $10.1017 / S 0033291708003681$

Hammer, M. S., Swinburn, T. K., and Neitzel, R. L. (2014). Environmental noise pollution in the United States: developing an effective public health response. Environ. Health Perspect. 122, 115-119. doi: 10.1289/ehp.1307272

Hänninen, O., Knol, A. B., Jantunen, M., Lim, T.-A., Conrad, A., Rappolder, M., et al. (2014). Environmental burden of disease in europe: assessing nine risk factors in six countries. Environ. Health Perspect. 122, 439-446. doi: 10.1289/ehp.1206154

Hardin, P. J., and Jensen, R. R. (2007). The effect of urban leaf area on summertime urban surface kinetic temperatures: a terre haute case study. Urban For. Urban Green. 6, 63-72. doi: 10.1016/j.ufug.2007.01.005

Harmsen, M. J. H. M., van Dorst, P., van Vuuren, D. P., van den Berg, M., Van Dingenen, R., and Klimont, Z. (2020). Co-benefits of black carbon mitigation for climate and air quality. Clim. Change 163, 1519-1538. doi: $10.1007 / \mathrm{s} 10584-020-02800-8$

Heat Resilient Cities Benefits Tool. (2020). Heat Resilient Cities Benefits Tool. [WWW Document] 2020. Glob. Heat Health Inf. Netw. Available online at: https://ghhin.org/resources/heat-resilient-cities-benefits-tool/ (accessed June $18,2021)$.

Heaviside, C., Macintyre, H., and Vardoulakis, S. (2017). The Urban Heat Island: implications for health in a changing environment. Curr. Environ. Health Rep. 4, 296-305. doi: 10.1007/s40572-017-0150-3

Helbich, M. (2019). Spatiotemporal contextual uncertainties in green space exposure measures: exploring a time series of the normalized difference vegetation indices. Int. J. Environ. Res. Public Health 16, 852. doi: 10.3390/ijerph16050852

Hess, J. J., Ranadive, N., Boyer, C., Aleksandrowicz, L., Anenberg, S. C., Aunan, K., et al. (2020). Guidelines for modeling and reporting health effects of climate change mitigation actions. Environ. Health Perspect. 128, 115001. doi: 10.1289/EHP6745

International Energy Agency. (2021). Net Zero by (2050). - A Roadmap for the Global Energy Sector.

IPCC (2018). Global Warming of $1.5^{\circ} \mathrm{C}$. IPCC.

Jack, D. W., and Kinney, P. L. (2010). Health co-benefits of climate mitigation in urban areas. Curr. Opin. Environ. Sustain. 2, 172-177. doi: 10.1016/j.cosust.2010.06.007

James, P., Hart, J. E., Banay, R. F., and Laden, F. (2016). Exposure to greenness and mortality in a nationwide prospective cohort study of women. Environ. Health Perspect. 124, 1344-1352. doi: 10.1289/ehp.1510363

Janssen, I., and LeBlanc, A. G. (2010). Systematic review of the health benefits of physical activity and fitness in school-aged children and youth. Int. J. Behav. Nutr. Phys. Act. 7, 40. doi: 10.1186/1479-5868-7-40

Jarosińska, D., Héroux, M.-È., Wilkhu, P., Creswick, J., Verbeek, J., Wothge, J., et al. (2018). Development of the WHO environmental noise guidelines for the European region: an introduction. Int. J. Environ. Res. Public Health 15, 813. doi: 10.3390/ijerph15040813

Jenkin, M. E., Young, J. C., and Rickard, A. R. (2015). The MCM v3.3.1 degradation scheme for isoprene. Atmospheric Chem. Phys. 15, 11433-11459. doi: 10.5194/acp-15-11433-2015

Jiang, Y. Y., Yang, Z. X., Ni, R., Zhu, Y. Q., Li, Z. Y., Yang, L. C., et al. (2013). Effectiveness analysis on the physical activity and the health benefit of a community population based program. Biomed. Environ. Sci. 26, 468-473. doi: 10.3967/0895-3988.2013.06.007

Johnson, S., Haney, J., Cairone, L., Huskey, C., and Kheirbek, I. (2020). Assessing air quality and public health benefits of New York city's climate action plans. Environ. Sci. Technol. 54, 9804-9813. doi: 10.1021/acs.est.0c00694

Johnston, J. E., Juarez, Z., Navarro, S., Hernandez, A., and Gutschow, W. (2019). Youth engaged participatory air monitoring: a 'day in the life' in urban 
environmental justice communities. Int. J. Environ. Res. Public Health 17, 93. doi: 10.3390/ijerph17010093

Kabisch, N., Haase, D., and Annerstedt van den Bosch, M. (2016). Adding natural areas to social indicators of intra-urban health inequalities among children: a case study from Berlin, Germany. Int. J. Environ. Res. Public Health 13, 783. doi: 10.3390/ijerph13080783

Kalsch, H., Hennig, F., Moebus, S., Mohlenkamp, S., Dragano, N., Jakobs, H., et al. (2014). Are air pollution and traffic noise independently associated with atherosclerosis: the Heinz Nixdorf recall study. Eur. Heart J. 35, 853-860. doi: 10.1093/eurheartj/eht426

Kelly, P., Kahlmeier, S., Götschi, T., Orsini, N., Richards, J., Roberts, N., et al. (2014). Systematic review and meta-analysis of reduction in all-cause mortality from walking and cycling and shape of dose response relationship. Int. J. Behav. Nutr. Phys. Act. 11, 132. doi: 10.1186/s12966-014-0132-x

Khreis, H., Kelly, C., Tate, J., Parslow, R., Lucas, K., and Nieuwenhuijsen, M. (2017). Exposure to traffic-related air pollution and risk of development of childhood asthma: a systematic review and meta-analysis. Environ. Int. 100, 1-31. doi: 10.1016/j.envint.2016.11.012

Kohl, D. H. W. (2012). The pandemic of physical inactivity: global action for public health Lancet 380, 294-305. doi: 10.1016/S0140-6736(12)60898-8

Kruize, H., van der Vliet, N., Staatsen, B., Bell, R., Chiabai, A., Muiños, G., et al. (2019). Urban green space: creating a triple win for environmental sustainability, health, and health equity through behavior change. Int. J. Environ. Res. Public Health 16, 4403. doi: 10.3390/ijerph16224403

Kuylenstierna, J. C. I., Heaps, C. G., Ahmed, T., Vallack, H. W., Hicks, W. K., Ashmore, M. R., et al. (2020). Development of the Low Emissions Analysis Platform - Integrated Benefits Calculator (LEAP-IBC) tool to assess air quality and climate co-benefits: application for Bangladesh. Environ. Int. 145, 106155. doi: 10.1016/j.envint.2020.106155

Lara-Valencia, F., Álvarez-Hernández, G., Harlow, S. D., Denman, C., and García-Pérez, H. (2012). Neighborhood socio-environmental vulnerability and infant mortality in Hermosillo, Sonora. Salud Pública Méx. 54, 367-374. doi: 10.1590/S0036-36342012000400006

Lee, N. F. (2021). Spatial and sociodemographic determinants of community loudness perception. Appl. Acoust. 10, 108459. doi: 10.1016/j.apacoust.2021.108459

Lehtomäki, H., Korhonen, A., Asikainen, A., Karvosenoja, N., Kupiainen, K., Paunu, V.-V., et al. (2018). Health impacts of ambient air pollution in Finland. Int. J. Environ. Res. Public Health 15, 736. doi: 10.3390/ijerph15040736

Lelieveld, J., Pozzer, A., Pöschl, U., Fnais, M., Haines, A., and Münzel, T. (2020). Loss of life expectancy from air pollution compared to other risk factors: a worldwide perspective. Cardiovasc. Res. 116, 1910-1917. doi: $10.1093 /$ cvr/cvaa025

Liu, J., Clark, L. P., Bechle, M., Hajat, A., Kim, S.-Y., Robinson, A., et al. (2021). Disparities in air pollution exposure in the United States by race-ethnicity and income, 1990-2010. ChemRxiv. doi: 10.26434/chemrxiv.13814711.v2

Lõhmus, M., and Balbus, J. (2015). Making green infrastructure healthier infrastructure. Infect. Ecol. Epidemiol. 5, 30082. doi: 10.3402/iee.v5.30082

Maas, J., van Dillen, S. M. E., Verheij, R. A., and Groenewegen, P. P. (2009). Social contacts as a possible mechanism behind the relation between green space and health. Health Place 15, 586-595. doi: 10.1016/j.healthplace.2008.09.006

Markandya, A., and Sampedro, J. (2020). "Health co-benefits of climate mitigation policies: why is it so hard to convince policy-makers of them and what can be done to change that?" in Ancillary Benefits of Climate Policy: New Theoretical Developments and Empirical Findings, Springer Climate, editors W. Buchholz, A. Markandya, D. Rübbelke, and S. Vögele (Cham: Springer International Publishing), 227-241. doi: 10.1007/978-3-030-30978-7_13

Markandya, A., Sampedro, J., Smith, S. J., Van Dingenen, R., Pizarro-Irizar, C., Arto, I., et al. (2018). Health co-benefits from air pollution and mitigation costs of the Paris Agreement: a modelling study. Lancet Planet. Health 2, e126-e133. doi: 10.1016/S2542-5196(18)30029-9

Martin, R. V., Brauer, M., van Donkelaar, A., Shaddick, G., Narain, U., and Dey, S. (2019). No one knows which city has the highest concentration of fine particulate matter. Atmospheric Environ. 3, 100040. doi: 10.1016/j.aeaoa.2019.100040

McDuffie, E. E., Martin, R. V., Spadaro, J. V., Burnett, R., Smith, S. J., O’Rourke, P., et al. (2021). Source sector and fuel contributions to ambient PM2.5 and attributable mortality across multiple spatial scales. Nat. Commun. 12, 3594. doi: 10.1038/s41467-021-23853-y

McEachan, R. R. C., Prady, S. L., Smith, G., Fairley, L., Cabieses, B., Gidlow, C., et al. (2016). The association between green space and depressive symptoms in pregnant women: moderating roles of socioeconomic status and physical activity. J. Epidemiol. Community Health 70, 253-259. doi: 10.1136/jech-2015-205954

Mindell, J., and Joffe, M. (2003). Health impact assessment in relation to other forms of impact assessment. J. Public Health 25, 107-112. doi: 10.1093/pubmed/fdg024

Monninkhof, E. M., Elias, S. G., Vlems, F. A., van der Tweel, I., Schuit, A. J., Voskuil, D. W., et al. (2007). Physical activity and breast cancer: a systematic review. Epidemiology 18, 137-157. doi: 10.1097/01.ede.0000251167.75581.98

Moran, D., Kanemoto, K., Jiborn, M., Wood, R., Többen, J., and Seto, K. C. (2018). Carbon footprints of 13000 cities. Environ. Res. Lett. 13, 064041. doi: 10.1088/1748-9326/aac72a

Moran, M. R., Rodríguez, D. A., Cotinez-O'Ryan, A., and Miranda, J. J. (2020). Park use, perceived park proximity, and neighborhood characteristics: evidence from 11 cities in Latin America. Cities 105, 102817. doi: 10.1016/j.cities.2020.102817

Moss, J. L., Doick, K. J., Smith, S., and Shahrestani, M. (2019). Influence of evaporative cooling by urban forests on cooling demand in cities. Urban For. Urban Green. 37, 65-73. doi: 10.1016/j.ufug.2018.07.023

Mueller, N., Rojas-Rueda, D., Basagaña, X., Cirach, M., Cole-Hunter, T., Dadvand, P., et al. (2017). Urban and transport planning related exposures and mortality: a health impact assessment for cities. Environ. Health Perspect. 125, 89-96. doi: 10.1289/EHP220

Munzel, T., Gori, T., Babisch, W., and Basner, M. (2014). Cardiovascular effects of environmental noise exposure. Eur. Heart J. 35, 829-836. doi: 10.1093/eurheartj/ehu030

Negele, L., Flexeder, C., Koletzko, S., Bauer, C.-P., von Berg, A., Berdel, D., et al. (2020). Association between objectively assessed physical activity and sleep quality in adolescence. Results from the GINIplus and LISA studies. Sleep Med. 72, 65-74. doi: 10.1016/j.sleep.2020.03.007

Nesbitt, L., Meitner, M. J., Sheppard, S. R. J., and Girling, C. (2018). The dimensions of urban green equity: a framework for analysis. Urban For. Urban Green. 34, 240-248. doi: 10.1016/j.ufug.2018.07.009

Nieuwenhuijsen, M. J., and Khreis, H. (2016). Car free cities: pathway to healthy urban living. Environ. Int. 94, 251-262. doi: 10.1016/j.envint.2016.05.032

Norton, B. A., Coutts, A. M., Livesley, S. J., Harris, R. J., Hunter, A. M., and Williams, N. S. G. (2015). Planning for cooler cities: a framework to prioritise green infrastructure to mitigate high temperatures in urban landscapes. Landsc. Urban Plan. 134, 127-138. doi: 10.1016/j.landurbplan.2014.10.018

Nowak, D. J., Hirabayashi, S., Bodine, A., and Greenfield, E. (2014). Tree and forest effects on air quality and human health in the United States. Environ. Pollut. 193, 119-129. doi: 10.1016/j.envpol.2014.05.028

Önder, S., and Akay, A. (2014). The roles of plants on mitigating the urban heat islands' negative effects. Int. J. Agric. Econ. Dev. 2, 18-32.

Orellano, P., Quaranta, N., Reynoso, J., Balbi, B., and Vasquez, J. (2017). Effect of outdoor air pollution on asthma exacerbations in children and adults: Systematic review and multilevel metaanalysis. PLoS ONE 12:e0174050. doi: 10.1371/journal.pone.01 74050

Osborne, M. T., Radfar, A., Hassan, M. Z. O., Abohashem, S., Oberfeld, B., Patrich, T., et al. (2020). A neurobiological mechanism linking transportation noise to cardiovascular disease in humans. Eur. Heart J. 41, 772-782. doi: 10.1093/eurheartj/ehz820

Padeiro, M., Louro, A., and da Costa, N. M. (2019). Transit-oriented development and gentrification: a systematic review. Transp. Rev. 39, 733-754. doi: 10.1080/01441647.2019.1649316

Peters, R., Ee, N., Peters, J., Booth, A., Mudway, I., and Anstey, K. J. (2019). Air pollution and dementia: a systematic review. J. Alzheimers. Dis. 70, S145-S163. doi: 10.3233/JAD-180631

Raifman, M., Lambert, K. F., Levy, J. I., and Kinney, P. L. (2021). Mortality implications of increased active mobility for a proposed regional transportation emission cap-and-invest program. J. Urban Health 98, 315-327. doi: 10.1007/s11524-020-00510-1 
Raji, B., Tenpierik, M. J., and van den Dobbelsteen, A. (2015). The impact of greening systems on building energy performance: a literature review. Renew. Sustain. Energy Rev. 45, 610-623. doi: 10.1016/j.rser.2015.02.011

Rizwan, A. M., Dennis, L. Y. C., and Liu, C. (2008). A review on the generation, determination and mitigation of Urban Heat Island. J. Environ. Sci. 20, 120-128. doi: 10.1016/S1001-0742(08)60019-4

Rojas-Rueda, D., Nieuwenhuijsen, M. J., Gascon, M., Perez-Leon, D., and Mudu, P. (2019). Green spaces and mortality: a systematic review and meta-analysis of cohort studies. Lancet Planet. Health 3, e469-e477. doi: 10.1016/S2542-5196(19)30215-3

Rosenzweig, C., Solecki, W., Hammer, S. A., and Mehrotra, S. (2010). Cities lead the way in climate-change action. Nature 467, 909-911. doi: 10.1038/467909a

Sacks, J., Fann, N., Gumy, S., Kim, I., Ruggeri, G., and Mudu, P. (2020). Quantifying the public health benefits of reducing air pollution: critically assessing the features and capabilities of WHO's AirQ+ and U.S. EPA's Environmental Benefits Mapping and Analysis Program-Community Edition (BenMAP-CE). Atmosphere 11, 516. doi: 10.3390/atmos11050516

Sacks, J. D., Lloyd, J. M., Zhu, Y., Anderton, J., Jang, C. J., Hubbell, B., et al. (2018). The Environmental Benefits Mapping and Analysis Program Community Edition (BenMAP-CE): a tool to estimate the health and economic benefits of reducing air pollution. Environ. Model. Softw. 104, 118-129. doi: 10.1016/j.envsoft.2018.02.009

Sampedro, J. (2020). Health co-benefits and mitigation costs as per the Paris Agreement under different technological pathways for energy supply. Environ. Int. 136, 105513. doi: 10.1016/j.envint.2020.105513

Shafique, M., Kim, R., and Lee, D. (2016). The potential of green-blue roof to manage storm water in urban areas. Nat. Environ. Pollut. Technol. 15, 715-718.

Shin, S., Bai, L., Oiamo, T. H., Burnett, R. T., Weichenthal, S., Jerrett, M., et al. (2020). Association between road traffic noise and incidence of diabetes mellitus and hypertension in Toronto, Canada: a population-based cohort study. J. Am. Heart Assoc. 9, e013021. doi: 10.1161/JAHA.119.013021

Shindell, D., Kuylenstierna, J. C. I., Vignati, E., van Dingenen, R., Amann, M., Klimont, Z., et al. (2012). Simultaneously mitigating near-term climate change and improving human health and food security. Science 335, 183-189. doi: 10.1126/science. 1210026

Siddiqui, I. A., Nizami, S., Chandio, R. R., Nizami, S., Sikandetr, N., and Ashraf, S. (2015). Consequences of traffic noise in residents of Karachi, Pakistan. Pak. J. Med. Sci. 31, 448-452. doi: 10.12669/pjms.312.6367

Smith, A. D., Crippa, A., Woodcock, J., and Brage, S. (2016). Physical activity and incident type 2 diabetes mellitus: a systematic review and dose-response meta-analysis of prospective cohort studies. Diabetologia 59, 2527-2545. doi: 10.1007/s00125-016-4079-0

Solecki, W. D., Rosenzweig, C., Parshall, L., Pope, G., Clark, M., Cox, J., et al. (2005). Mitigation of the heat island effect in urban New Jersey. Environ. Hazards 6, 39-49. doi: 10.1016/j.hazards.2004.12.002

Sørensen, M., Andersen, Z. J., Nordsborg, R. B., Becker, T., Tjønneland, A., Overvad, K., et al. (2013). Long-term exposure to road traffic noise and incident diabetes: a cohort study. Environ. Health Perspect. 121, 217-222. doi: 10.1289/ehp.1205503

Southerland, V. A., Anenberg, S. C., Harris, M., Apte, J., Hystad, P., van Donkelaar, A., et al. (2021). Assessing the distribution of air pollution health risks within cities: a neighborhood-scale analysis leveraging high-resolution data sets in the Bay Area, California. Environ. Health Perspect. 129, 37006. doi: 10.1289/EHP7679

Symonds, P., Milner, J., Mohajeri, N., Aplin, J., Hale, J., J., et al. (2021). A tool for assessing the climate change mitigation and health impacts of environmental policies: the Cities Rapid Assessment Framework for Transformation (CRAFT). Wellcome Open Res. 5, 269. doi: 10.12688/wellcomeopenres.1 6345.2

Tessum, C. W., Apte, J. S., Goodkind, A. L., Muller, N. Z., Mullins, K. A., Paolella, D. A., et al. (2019). Inequity in consumption of goods and services adds to racial-ethnic disparities in air pollution exposure. Proc. Natl. Acad. Sci. U.S.A. 116, 6001-6006. doi: 10.1073/pnas.1818859116

Tessum, C. W., Paolella, D. A., Chambliss, S. E., Apte, J. S., Hill, J. D., and Marshall, J. D. (2021). PM2.5 polluters disproportionately and systemically affect people of color in the United States. Sci. Adv. 7, eabf4491. doi: 10.1126/sciadv.abf4491

Theakston, F., Fritschi, L., Lex Brown, A., Rokho, K., Dietrich, S., and Kephalopoulos, S. (eds.). (2011). Burden of Disease From Environmental Noise:
Quantification of Healthy Life Years Lost in Europe. World Health Organization, Regional Office for Europe, Copenhagen.

Twohig-Bennett, C., and Jones, A. (2018). The health benefits of the great outdoors: a systematic review and meta-analysis of greenspace exposure and health outcomes. Environ. Res. 166, 628-637. doi: 10.1016/j.envres.2018.06.030

ULEZ (2019). How does London's new emissions zone compare? BBC News.

UN-Habitat. (2015). Guiding Principles for City Climate Action Planning.

US EPA (1974). Information on Levels of Environmental Noise Requisite to Protect Public Health and Welfare with an Adequate Margin of Safety.

US EPA. (2015). Regulatory Impact Analysis for the Clean Power Plan Final Rule.

US EPA. (2019). Integrated Science Assessment (ISA) for Particulate Matter (Final Report).

US EPA. (2020). Integrated Science Assessment for Ozone and Related Photochemical Oxidants.

U. S. Green Building Council. (2019). Acoustic performance [WWW Document]. Available online at: https://www.usgbc.org/credits/eq10 (accessed November 3, 2020).

van Heeswijk, W., Larsen, R., and Larsen, A. (2019). An urban consolidation center in the city of Copenhagen: a simulation study. Int. J. Sustain. Transp. 13, 675-691. doi: 10.1080/15568318.2018.1503380

van Kempen, E., and Babisch, W. (2012). The quantitative relationship between road traffic noise and hypertension: a meta-analysis. J. Hypertens. 30, 1075-1086. doi: 10.1097/HJH.0b013e328352ac54

Van Renterghem, T., Forssén, J., Attenborough, K., Jean, P., Defrance, J., Hornikx, M., et al. (2015). Using natural means to reduce surface transport noise during propagation outdoors. Appl. Acoust. 92, 86-101. doi: 10.1016/j.apacoust.2015.01.004

Vandyck, T., Keramidas, K., Tchung-Ming, S., Weitzel, M., and Van Dingenen, R. (2020). Quantifying air quality co-benefits of climate policy across sectors and regions. Clim. Change 163, 1501-1517. doi: 10.1007/s10584-020-02685-7

Walker, E. D., Lee, N. F., Scammell, M. K., Feuer, A. P., Power, M. B., Lane, K. J., et al. (2021). Descriptive characterization of sound levels in an environmental justice city before and during a global pandemic. Environ. Res. 199, 111353. doi: 10.1016/j.envres.2021.111353

Wang, T., Jiang, Z., Zhao, B., Gu, Y., Liou, K.-N., Kalandiyur, N., et al. (2020). Health co-benefits of achieving sustainable net-zero greenhouse gas emissions in California. Nat. Sustain. 3, 597-605. doi: 10.1038/s41893-020-0520-y

Watts, N., Amann, M., Arnell, N., Ayeb-Karlsson, S., Beagley, J., Belesova, K., et al. (2021). The 2020 report of The Lancet Countdown on health and climate change: responding to converging crises. Lancet 397, 129-170. doi: 10.1016/S0140-6736(20)32290-X

Wei, T., Wu, J., and Chen, S. (2021). Keeping track of greenhouse gas emission reduction progress and targets in 167 cities worldwide. Front. Sustain. Cities 3 , 696381. doi: $10.3389 /$ frsc.2021.696381

West, J. J., Smith, S. J., Silva, R. A., Naik, V., Zhang, Y., Adelman, Z., et al. (2013). Co-benefits of mitigating global greenhouse gas emissions for future air quality and human health. Nat. Clim. Change 3, 885-889. doi: 10.1038/nclimate2009

WHO Regional Office for Europe (2018). Environmental Noise Guidelines for the European Region

Wolch, J. R., Byrne, J., and Newell, J. P. (2014). Urban green space, public health, and environmental justice: the challenge of making cities 'just green enough.' Landsc. Urban Plan. 125, 234-244. doi: 10.1016/j.landurbplan.2014.01.017

Wolin, K. Y., Yan, Y., Colditz, G. A., and Lee, I.-M. (2009). Physical activity and colon cancer prevention: a meta-analysis. Br. J. Cancer 100, 611-616. doi: $10.1038 /$ sj.bjc. 6604917

Wong, N. H., and Yu, C. (2005). Study of green areas and urban heat island in a tropical city. Habitat Int. 29, 547-558. doi: 10.1016/j.habitatint.2004. 04.008

Woodcock, J., Edwards, P., Tonne, C., Armstrong, B. G., Ashiru, O., Banister, D., et al. (2009). Public health benefits of strategies to reduce greenhouse-gas emissions: urban land transport. Lancet 374, 1930-1943. doi: 10.1016/S0140-6736(09)61714-1

Woodcock, J., Franco, O. H., Orsini, N., and Roberts, I. (2011). Non-vigorous physical activity and all-cause mortality: systematic review and meta-analysis of cohort studies. Int. J. Epidemiol. 40, 121-138. doi: 10.1093/ije/dyq104

World Health Organization (ed.). (2021). WHO Global Air Quality Guidelines: Particulate Matter (PM2.5 and PM10), Ozone, Nitrogen Dioxide, Sulfur Dioxide and Carbon Monoxide. Geneva: World Health Organization. 
World Health Organization (ed.). (2006). Air Quality Guidelines: Global Update 2005: Particulate Matter, Ozone, Nitrogen Dioxide, and Sulfur Dioxide. Copenhagen: World Health Organization.

WRI. (n.d.). London's Ultra Low Emission Zone [WWW Document]. Prize Cities. Available online at: https://prizeforcities.org/project/ultra-low-emission-zone (accessed April 20, 2021).

Xie, Y., Wu, Y., Xie, M., Li, B., Zhang, H., Ma, T., et al. (2020). Health and economic benefit of China's greenhouse gas mitigation by 2050. Environ. Res. Lett. 15, 104042. doi: 10.1088/1748-9326/aba97b

Yang, J., Zhao, Y., Cao, J., and Nielsen, C. P. (2021). Co-benefits of carbon and pollution control policies on air quality and health till 2030 in China. Environ. Int. 152, 106482. doi: 10.1016/j.envint.2021.106482

Zhang, X., Chen, X., and Zhang, X. (2018). The impact of exposure to air pollution on cognitive performance. Proc. Natl. Acad. Sci. U.S.A. 115, 9193-9197. doi: 10.1073/pnas.1809474115

Ziter, C. D., Pedersen, E. J., Kucharik, C. J., and Turner, M. G. (2019). Scaledependent interactions between tree canopy cover and impervious surfaces reduce daytime urban heat during summer. Proc. Natl. Acad. Sci. U.S.A. 116, 7575. doi: $10.1073 /$ pnas. 1817561116
Conflict of Interest: The authors declare that the research was conducted in the absence of any commercial or financial relationships that could be construed as a potential conflict of interest.

Publisher's Note: All claims expressed in this article are solely those of the authors and do not necessarily represent those of their affiliated organizations, or those of the publisher, the editors and the reviewers. Any product that may be evaluated in this article, or claim that may be made by its manufacturer, is not guaranteed or endorsed by the publisher.

Copyright (๔ 2021 Castillo, Anenberg, Chafe, Huxley, Johnson, Kheirbek, Malik, Marshall, Naidoo, Nelson, Pendleton, Sun, van den Broek d'Obrenan and Kinney. This is an open-access article distributed under the terms of the Creative Commons Attribution License (CC BY). The use, distribution or reproduction in other forums is permitted, provided the original author(s) and the copyright owner(s) are credited and that the original publication in this journal is cited, in accordance with accepted academic practice. No use, distribution or reproduction is permitted which does not comply with these terms. 